\title{
Proceeding
}

Supplementary Issue: Rio 2016 Olympic Games Second Anniversary Special Edition. Olympic Studies Forum, 2-3 October 2018.

Federal University of Espirito Santo, (Vitória - Espirito Santo), Brazil

\section{Olympic education at the Rio 2016 Games: A georeferenced analysis}

\author{
FLAVIO VALDIR KIRST ${ }^{1}$, OTAVIO GUIMARAES TAVARES DA SILVA ${ }^{2}$ \\ ${ }^{1}$ Faculdades Doctum de Serra (DOCTUM), Serra, Espírito Santo, Brazil \\ ${ }^{2}$ Federal University of Espírito Santo (UFES), Vitória, Espírito Santo, Brazil
}

\begin{abstract}
Olympic Education can be defined as a set of education proposals through sport that has as reference the Olympic Movement, its values, symbols, history, heroes and traditions (TAVARES, 1998). Programs of Olympic Education of the Olympic Party since 1994 (NAUL et al., 2017). However, the scope of the programs is lagging behind (GRAVER et al., 2010; NIKOLAUS, 2013), a concern regarding concern with the International Olympic Committee (2014). The objective of this work was, based on techniques of georeferencing, consultation and reach of the Transformar Program, an Olympic education program of the organizing committee of the 2016 Olympic and Paralympic Games. Starting from a register of 24,665 teachers, the study mapped 12,527 schools where they worked the teachers reached by Transforma. The results were higher than the previous score in schools with a degree of development, concentrated in the region geographically more developed of the country, demonstrating a positive relation between the quality of teaching and the involvement with activities that enrich an educated education offered. Keywords: Olympism; Georeferencing; Olympic Games; Rio 2016.
\end{abstract}

\section{Cite this article as:}

Kirst, F.V., \& Tavares, O.G. (2019). Olympic education at the Rio 2016 Games: A georeferenced analysis (in Portuguese). Journal of Human Sport and Exercise, 14(3proc), S412-S422. doi:https://doi.org/10.14198/jhse.2019.14.Proc3.13

Corresponding author. Universidade Federal do Espírito Santo, Centro de Educação Física e Desportos, Departamento de Ginástica. Avenida Fernando Ferrari, 514, Departamento de Ginástica, Goiabeiras, 29075-910 - Vitória ES - Brazil.

E-mail: otavio.silva@ufes.br

Supplementary Issue: Rio 2016 Olympic Games Second Anniversary Special Edition. Olympic Studies Forum, 2-3 October 2018. Federal University of Espírito Santo, (Vitória - Espírito Santo), Brazil.

JOURNAL OF HUMAN SPORT \& EXERCISE ISSN 1988-5202

(c) Faculty of Education. University of Alicante

doi:10.14198/jhse.2019.14.Proc3.13

S412 | 2019 | Proc3 | VOLUME 14

(C) 2019 University of Alicante 


\section{INTRODUÇÃO}

O programa de educação dos Jogos Olímpicos e Paralímpicos Rio 2016 foi denominado Transforma. Em suas ações, o Transforma disponibilizou materiais didático-pedagógicos através da web, capacitou coordenadores pedagógicos, professores de educação física, lideranças estudantis (denominados agentes jovens), e tutores de agentes jovens. Organizou ainda desafios (gincanas), que mobilizavam a escola em torno de um tema olímpico, festivais escolares de experimentação de esportes olímpicos e paralímpicos, programas televisivos tematizando esporte e educação, e promoveu o intercâmbio cultural com 18 países.

Segundo os dados disponíveis no relatório oficial (Berbat, 2016), participaram do Programa Transforma 16.042 escolas, distribuídas em 3.038 cidades, em todos os estados da federação e distrito federal, atingindo mais de 8 milhões de alunos. Das escolas atendidas, 14.064 foram escolas da rede pública (sedo 6.092 escolas estaduais, 7.871 escolas municipais, 101 escolas federais) além de 1.894 escolas da rede particular.

Foram oferecidos cursos de 18 esportes a 2.003 professores de educação física em 180 cidades, 7 desafios escolares abordando temas relacionados aos Jogos Olímpicos do Rio (1.771 escolas em 713 cidades) e materiais pedagógicos distribuídos em formações presenciais e, principalmente, através de uma plataforma de ensino à distância, para três públicos específicos: coordenadores pedagógicos escolares $(n=4.942)$, professores de educação física $(n=9.299)$ e tutores de agentes jovens $(n=7.103)$. Foram formados 56.824 agentes jovens, crianças que atuaram como disseminadores dos valores olímpicos em suas escolas. Além disso, o programa organizou 24 festivais esportivos para a experimentação de esportes olímpicos e paralímpicos envolvendo 20.627 participantes. Finalmente, seu material digital foi baixado 63.350 vezes por 10.960 professores, que atendem a 8.812 escolas de 2.320 cidades.

O objetivo deste estudo foi identificar o perfil médio das escolas alcançadas pelo programa Transforma, considerando sua distribuição geográfica e o grau de desenvolvimento dos municípios onde estão inseridas, considerando as áreas de emprego e renda, saúde e, principalmente, educação.

Esta pesquisa se caracteriza como um estudo de levantamento de tipo descritivo. A partir dos dados cadastrais dos professores inscritos no Programa Transforma, composto por 29.441 registros, rastreamos ${ }^{1}$ e mapeamos as escolas onde esses professores atuam e, a partir de técnicas de georreferenciamento ${ }^{2}$ analisamos seus indicadores sociais, utilizando como referência o Índice FIRJAN de Desenvolvimento Municipal - IFDM ${ }^{3}$ (Firjan, 2018).

Entendemos que estudos como este podem ajudar a compreender 0 alcance da efetividade das iniciativas de Educação Olímpica conectadas aos Jogos Olímpicos.

\footnotetext{
${ }^{1}$ Rastreamos a localização das escolas utilizando seu código do INEP - Instituto Nacional de Estudos e Pesquisas Educacionais Anísio Teixeira.

2 "[...] Geoprocessamento é um conjunto de técnicas computacionais que opera sobre bases de dados (que são registros de ocorrências) georreferenciados, para os transformar em informação (que é um acréscimo de conhecimento) relevante [...] (XAVIER DA SILVA (2001, 12-13)".

${ }^{3}$ O IFDM - Índice FIRJAN de Desenvolvimento Municipal - é um estudo do Sistema FIRJAN que acompanha anualmente 0 desenvolvimento socioeconômico de todos os mais de 5 mil municípios brasileiros em três áreas de atuação: Emprego \& renda, Educação e Saúde. Criado em 2008, ele é feito, exclusivamente, com base em estatísticas públicas oficiais, disponibilizadas pelos ministérios do Trabalho, Educação e Saúde. De leitura simples, o índice varia de 0 (mínimo) a 1 ponto (máximo) para classificar o nível de cada localidade em quatro categorias: baixo (de 0 a 0,4$)$, regular $(0,4$ a 0,6$)$, moderado (de 0,6 a 0,8$)$ e alto $(0,8$ a 1 ) desenvolvimento. Ou seja, quanto mais próximo de 1 , maior 0 desenvolvimento da localidade (Fonte: http://www.firjan.com.brlifdm/, acesso em 31/10/2018).
} 


\section{ANÁLISE GEORREFERENCIADA}

De acordo com os dados oficiais (Berbat, 2016), o Programa Transforma atendeu cerca de 16 mil escolas brasileiras, em mais de 3 mil municípios de todos os estados da federação e do distrito federal, correspondendo a uma média superior a 5 escolas atendidas por município. No entanto, conforme se observa na Figura 1, esta distribuição não foi homogênea.

\section{FIGURA 1 - Distribuição do Transforma por região.}

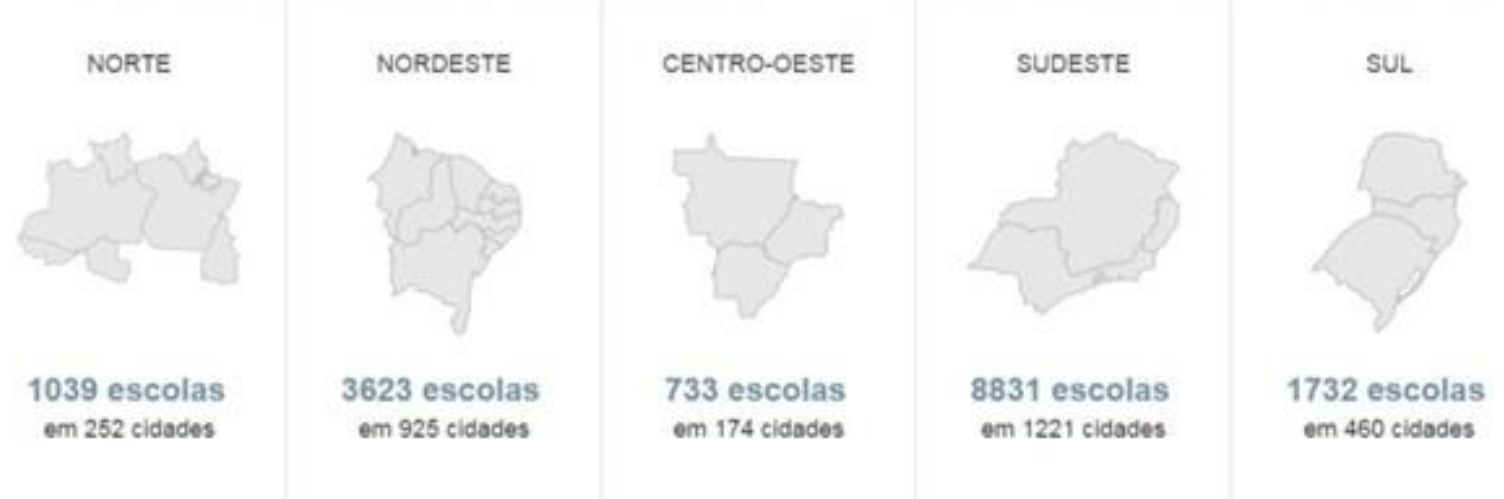

Fonte: Berbat (2016).

A maior concentração de escolas atendidas pelo programa se deu nos estados da região sudeste, que sozinha concentrou $55,3 \%$ das escolas atendidas. A região nordeste ocupa o segundo lugar, concentrando $22,7 \%$ das escolas (Gráfico 1). Juntas, as regiões sudeste e nordeste concentraram $78 \%$ de todas as escolas atendidas pelo Transforma. Como pode ser observado no Gráfico 1, essa tendência também é mantida em relação ao percentual de municípios alcançados por região, mas com menor magnitude.

GRÁFICO 1 - Distribuição de escolas e municípios alcançados por região.

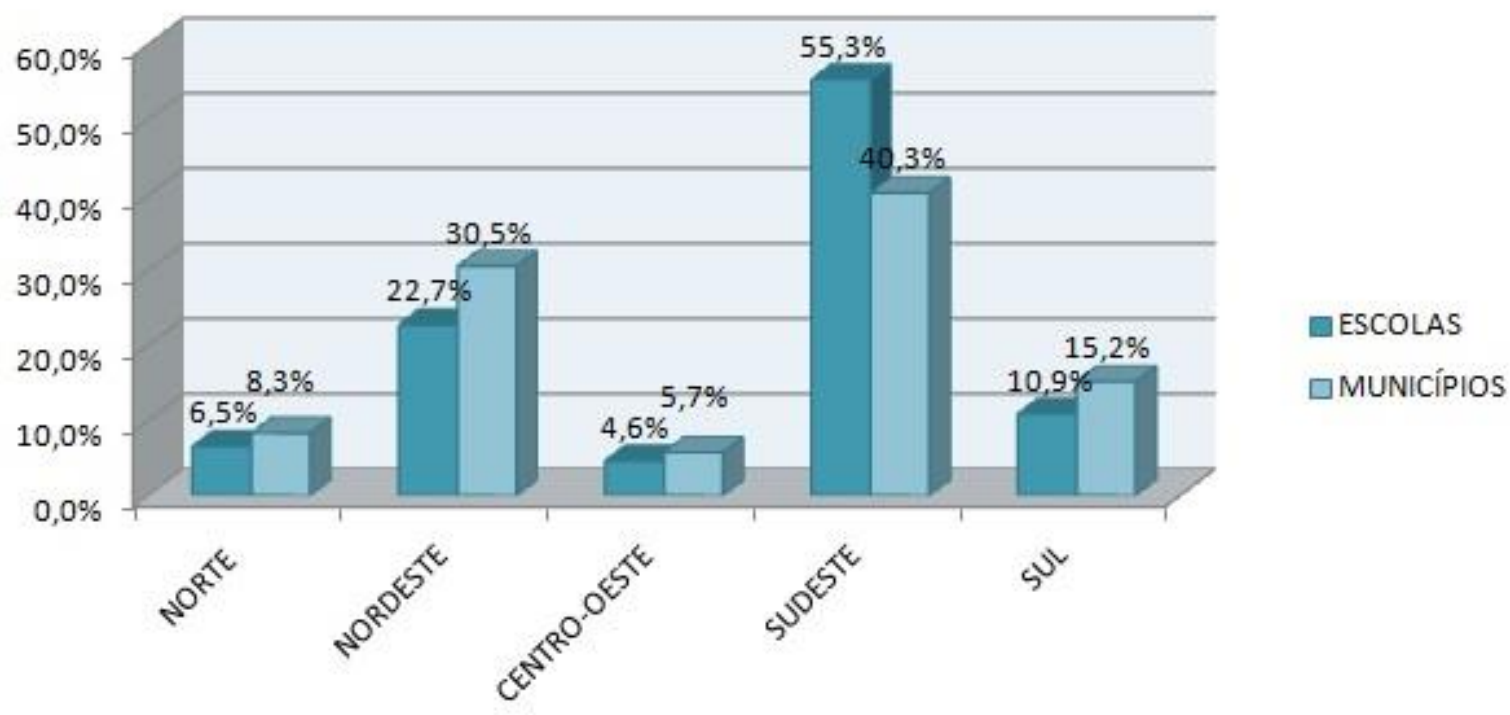




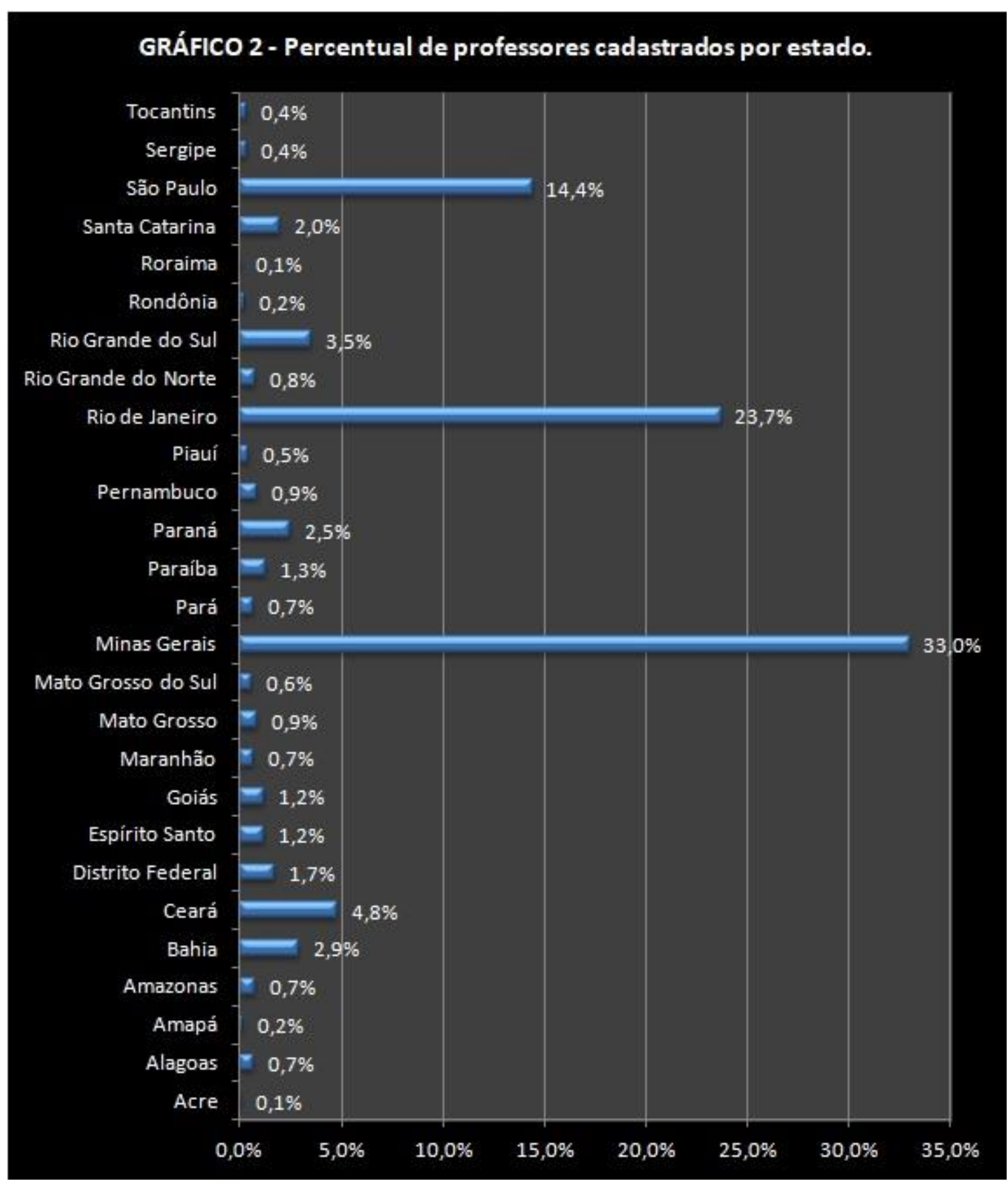

A região sudeste somou 40,3\% dos municípios alcançados pelo Transforma e, por ter concentrado o maior percentual de escolas $(55,3 \%)$, apresentou uma média de 7,2 escolas atendidas por município. Esta foi a única região do Brasil onde isso ocorreu, o que pode ser explicado pela maior incidência de atividades do Transforma na região sudeste, pela proximidade geográfica com a sede dos Jogos e por ser a região onde se concentram as cidades mais populosas do país. Nas demais regiões, o percentual de escolas é sempre menor do que o percentual de municípios alcançados na região, de forma que a média de escolas atendidas por município foi menor, apresentando números muito semelhantes entre si: média de 4,1 escolas na região norte, 4,2 na região centro-oeste, 3,8 na região sul e 3,9 na região nordeste. Importante observar que a região nordeste novamente se destaca, concentrando $30,5 \%$ dos municípios alcançados. Observa-se 
grande representação do programa nas regiões sudeste e nordeste que, juntas, concentraram $70,8 \%$ de todos os municípios alcançados pelo Transforma.

Partindo do cadastro geral do Transforma, que nos foi disponibilizado pelos gestores do programa oficial de educação do Comitê Organizador dos Jogos Olímpicos e Paralímpicos Rio 2016, composto por 24.665 registros de professores, identificamos o estado, município e escola ou escolas (vários professores cadastrados atuam em mais de uma escola) em que cada professor atua. Observa-se que $72,4 \%$ do total nacional de professores cadastrados no programa Transforma atuam em escolas da região sudeste. Três estados desta região se destacam: Rio de Janeiro, onde atuam $23,7 \%$ do total de professores cadastrados; São Paulo, com 14,4\% dos professores; e Minas Gerais, com 33,0\% deste universo, sendo este o estado com a maior concentração de professores cadastrados no Transforma entre todos os estados brasileiros. Juntos, esses três estados concentraram $71,1 \%$ do universo de professores cadastrados no Programa Transforma. O Gráfico 2 apresenta a distribuição total dos professores castrados no Programa Transforma nos 27 estados brasileiros.

Dentre todos os municípios brasileiros, concentrando $16,4 \%$ dos professores cadastrados no Transforma, destaca-se a região metropolitana do Rio de Janeiro ${ }^{4}$. Somente a cidade do Rio de Janeiro concentrou $10,4 \%$ do total dos professores inscritos no programa, o que, por certo, está associado à proximidade com a sede dos Jogos e das ações presenciais do Transforma.

Assim, constata-se que as regiões sudeste e nordeste do país concentraram a maior parte das ações do Programa Transforma, somando juntas quase $80 \%$ do total das escolas e mais de $70 \%$ dos municípios alcançados. Foram, sem dúvida, as duas regiões que mais se beneficiaram do programa. No entanto, dentre todos os estados que compõe essas duas regiões, três deles, todos da região sudeste, se destacam por concentrarem sozinhos mais de $70 \%$ dos multiplicadores do programa, os professores: Minas Gerais, São Paulo e Rio de Janeiro.

\section{GRÁFICO 3 - Localização dos municípios alcançados pelo Transforma.}

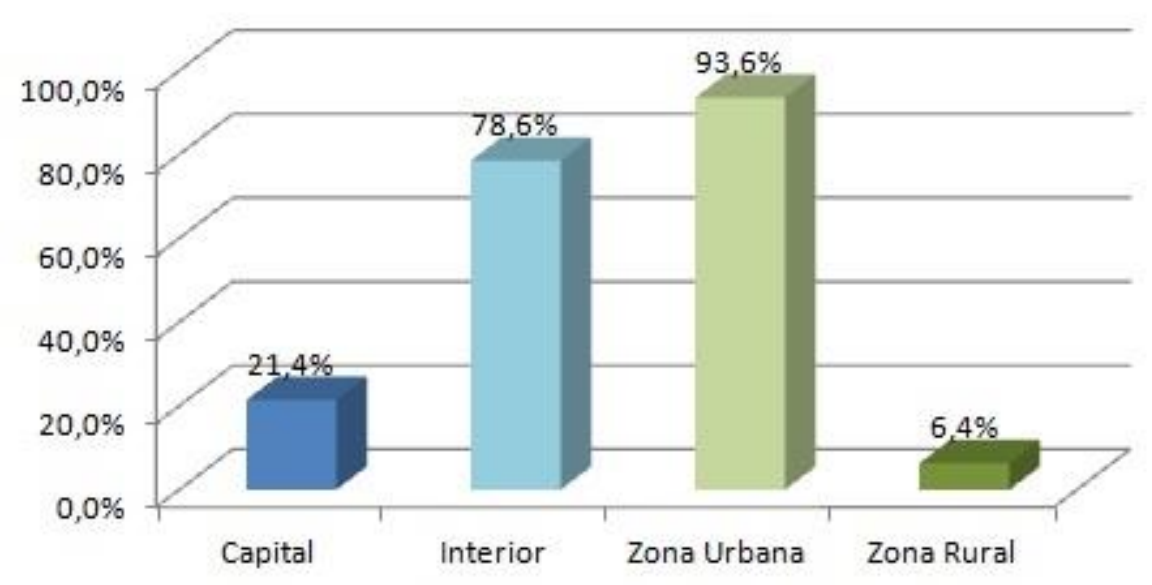

\footnotetext{
${ }^{4}$ A região metropolitana do Rio de Janeiro é composta por 17 municípios: Rio de Janeiro, Belford Roxo, Duque de Caxias, Guapimirim, Itaboraí, Japeri, Magé, Nilópolis, Niterói, Nova Iguaçu, Paracambi, Queimados, São Gonçalo, São João de Meriti, Seropédica, Mesquita e Tanguá.
} 
Após filtrarmos os dados do cadastro geral de professores do Transforma, identificamos 12.527 escolas atendidas. Observou-se que $78,6 \%$ dessas escolas estão localizadas em municípios do interior dos estados, e $21,4 \%$ nas capitais. $93,6 \%$ das escolas estão localizadas na zona urbana, enquanto apenas $6,4 \%$ na zona rural. Portanto, constata-se que o Programa Transforma teve como principais beneficiárias escolas localizadas na zona urbana de cidades do interior dos estados brasileiros. Essa distribuição pode ser mais bem visualizada no Gráfico 3.

Com o objetivo de melhor caracterizarmos as escolas atendidas pelo Transforma, utilizamos o Índice FIRJAN de Desenvolvimento Municipal ${ }^{5}$ (IFDM). Um dos índices de desenvolvimento de maior prestígio devido às bases de dados que utiliza em sua metodologia, o IFDM é referência para o acompanhamento do desenvolvimento socioeconômico brasileiro. O IFDM acompanha três áreas: "1) Emprego \& Renda, 2) Educação e 3) Saúde (Firjan, 2018, p. 7)”. A Figura 2 apresenta as categorias que compõem este índice.

FIGURA 2 - Resumo dos componentes do IFDM por área de desenvolvimento.

\begin{tabular}{|c|c|c|}
\hline \multicolumn{3}{|c|}{ IFDM } \\
\hline Emprego\&Renda & Educação & Saúde \\
\hline $\begin{array}{l}\text { - Geraçäo de emprego formal } \\
\text { - Taxa de formalização do } \\
\text { mercado de trabalho } \\
\text { - Geração de renda } \\
\text { - Massa salarial real no mercado } \\
\text { de trabalho formal } \\
\text { - Indice de Gini de desigualdade } \\
\text { de renda no trabalho formal }\end{array}$ & $\begin{array}{l}\text { - Atendimento à educaçăo infantil } \\
\text { - Abandono no ensino } \\
\text { fundamental } \\
\text { - Distorçäo idade-série no ensino } \\
\text { fundamental } \\
\text { - Docentes com ensino superior } \\
\text { no ensino fundamental } \\
\text { - Mèdia de horas-aula diárias no } \\
\text { ensino fundamental } \\
\text { - Resultado do IDEB no ensino } \\
\text { fundamental }\end{array}$ & $\begin{array}{l}\text { - Proporção de atendimento } \\
\text { adequado de pré-natal } \\
\text { - Obitos por causas mal definidas } \\
\text { - Obitos infantis por causas } \\
\text { evitáveis } \\
\text { - Internação sensivel à atenção } \\
\text { básica (ISAB) }\end{array}$ \\
\hline $\begin{array}{l}\text { Fonte: Ministerio do Trabalho e } \\
\text { Emprego }\end{array}$ & Fonte: Ministerio da Educaçào & Fonte: Ministerio da Saude \\
\hline
\end{tabular}

Fonte: FIRJAN (2018, p. 9).

O índice varia de 0 a 1 ponto, e classifica o nível de desenvolvimento de cada município segundo quatro categorias: baixo estágio de desenvolvimento (de 0 a 0,4$)$, desenvolvimento regular $(0,4$ a 0,6$)$, desenvolvimento moderado (de 0,6 a 0,8$)$ e alto estágio de desenvolvimento (0,8 a 1). Em outras palavras, quanto mais próximo de 1, maior o desenvolvimento da localidade (ver Figura 3).

50 IFDM - Índice FIRJAN de Desenvolvimento Municipal - é um estudo do Sistema FIRJAN que acompanha anualmente 0 desenvolvimento socioeconômico de todos os mais de 5 mil municípios brasileiros em três áreas de atuação: Emprego \& renda, Educação e Saúde. Criado em 2008, ele é feito, exclusivamente, com base em estatísticas públicas oficiais, disponibilizadas pelos ministérios do Trabalho, Educação e Saúde. (Fonte: http://www.firjan.com.br/ifdm/, acesso em 31/10/2018). 
FIGURA 3 - Niveis de desenvolvimento do indice FIRJAN

Alto desenvolvimento: resultados superiores a 0,8 ponto.

Desenvolvimento regular: resultados compreendidos entre 0,4 e 0,6 ponto.
Desenvolvimento moderado: resultados compreendidos entre 0,6 e 0,8 ponto.

Fonte: http//www. firjan.com.br/ifdm/ (acesso em 31/10/2018).

A média do IFDM dos municípios alcançados pelo Transforma foi de 0,73 , ao passo que a mediana foi de 0,76. Esses resultados estão bem acima da média nacional no ano de 2016, que foi de 0,6678 (Firjan, 2018). Em percentuais absolutos, $34,4 \%$ dos municípios alcançados pelo Transforma apresentam alto estágio de desenvolvimento e $54,6 \%$ tem desenvolvimento moderado. Somando-se os dois, temos $89 \%$ dos municípios alcançados pelo programa com IFDM de moderado a alto. Apenas 10,8\% encontram-se em municípios de desenvolvimento regular, e $0,2 \%$ em municípios com baixo estágio de desenvolvimento (Gráfico 4). Esses dados sugerem uma correlação positiva entre o desenvolvimento municipal e a participação no Transforma.

\section{GRÁFICO 4 - Estágio de desenvolvimento dos municípios alcançados pelo Transforma.}

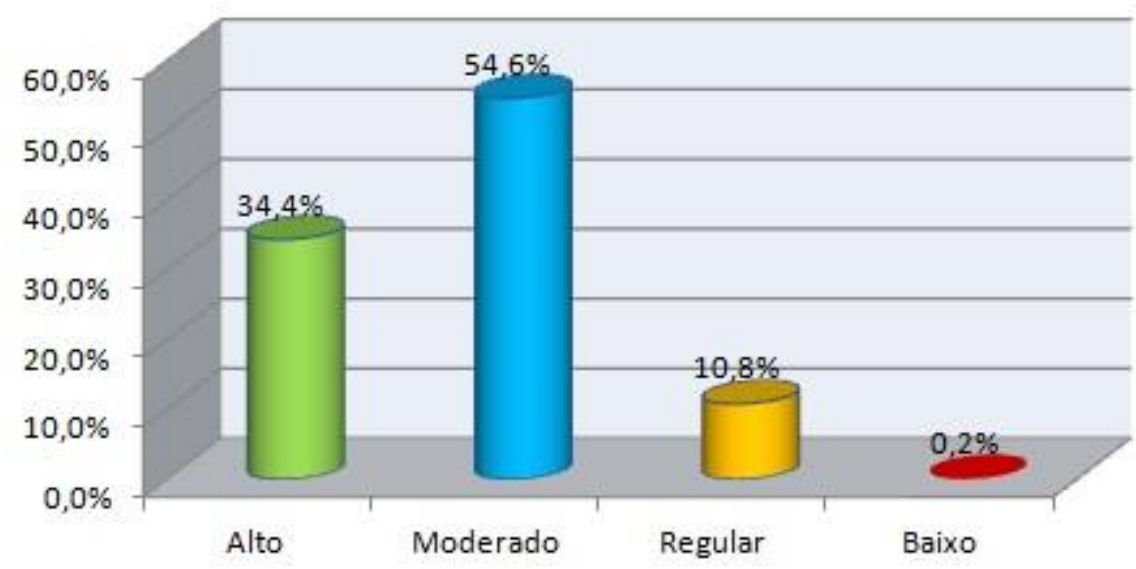

Esses números também superam em muito as médias nacionais, onde apenas $7 \%$ dos municípios apresentam alto desenvolvimento, 68,4\% desenvolvimento moderado, 23,5\% desenvolvimento regular e $0,2 \%$ baixo desenvolvimento (Firjan, 2018). Isso demonstra que o programa Transforma atingiu principalmente municípios com elevado estágio de desenvolvimento humano nas áreas de emprego e renda, educação e saúde (Gráfico 5). 


\section{GRÁFICO 5 - Comparação entre o estágio de desenvolvimento dos municípios alcançados pelo Transforma e a média nacional.}

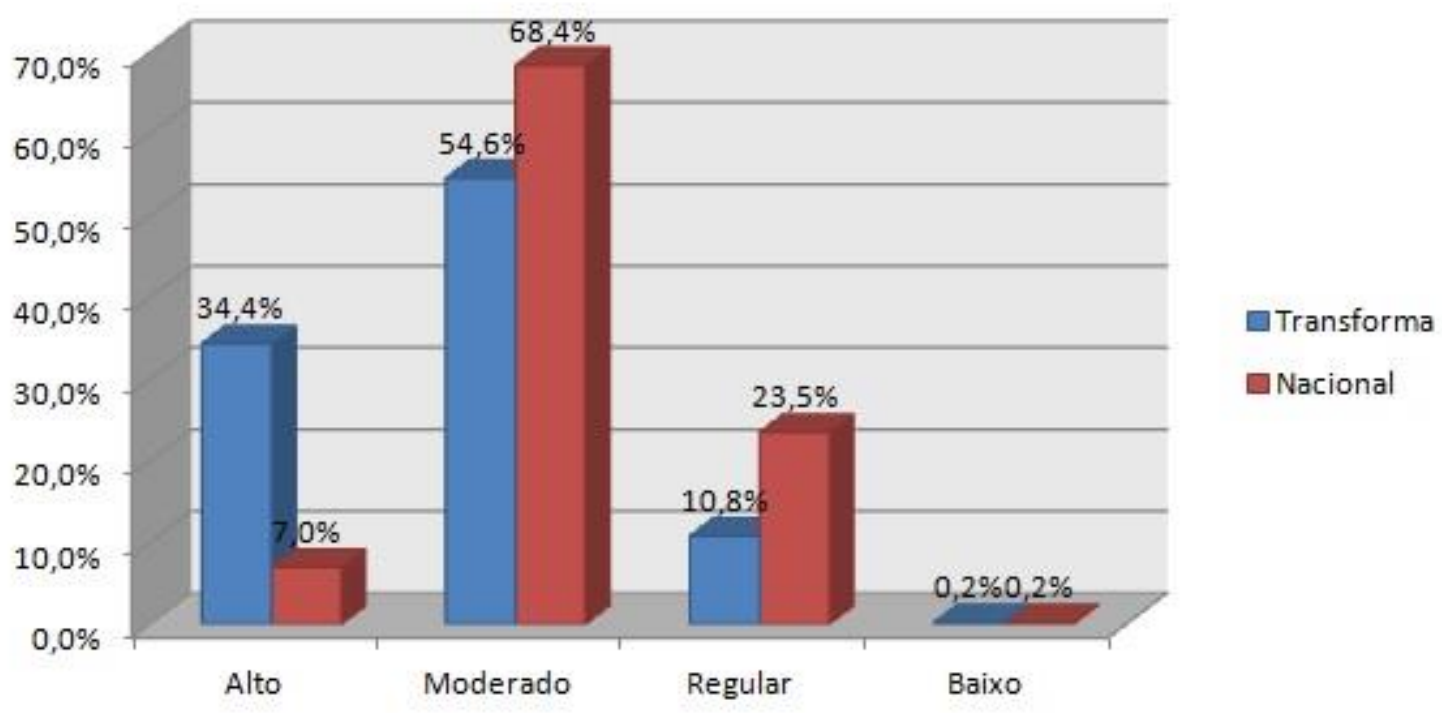

Ao tomarmos especificamente os números relativos à qualidade da educação dos municípios, os resultados são ainda mais expressivos. Em percentuais absolutos, $56,4 \%$ das escolas alcançadas pelo Transforma estão localizadas em municípios com alto estágio de desenvolvimento educacional, e 39,6\% em municípios com desenvolvimento moderado. Somando-se os dois, temos impressionantes $96 \%$ do universo de escolas cobertas pelo programa localizadas em municípios com o maior desenvolvimento educacional do país. Isso significa dizer que essas escolas que se destacam no atendimento à educação infantil, que apresentam baixo índice de abandono e de distorção entre a idade e a série no ensino fundamental, possuem docentes com formação superior e que trabalham com boa média de horas-aula diárias, além de serem escolas classificadas entre os melhores resultados no IDEB ${ }^{6}$. Apenas $4 \%$ das escolas encontram-se em municípios de desenvolvimento regular, e $0,0 \%$ em municípios que apresentam baixo estágio de desenvolvimento educacional. Esses percentuais estão representados no Gráfico 6.

Mais uma vez é possível observar que esses números superam a média nacional, onde $43,0 \%$ dos municípios apresentam alto desenvolvimento educacional, 48,5\% desenvolvimento moderado, 8,5\% desenvolvimento regular e $0,0 \%$ baixo desenvolvimento (Firjan, 2018). O programa Transforma atingiu principalmente municípios com alto estágio de desenvolvimento e, em menor grau, municípios com moderado estágio de desenvolvimento educacional, demonstrando uma tendência inversa ao padrão nacional (onde 0 desenvolvimento moderado é maior que 0 alto). A comparação entre 0 estágio de desenvolvimento educacional municipal das escolas atendidas pelo Transforma e a média nacional estão expressas no Gráfico 7.

\footnotetext{
60 Índice de Desenvolvimento da Educação Básica (Ideb) foi criado em 2007 e reúne, em um só indicador, os resultados de dois conceitos igualmente importantes para a qualidade da educação: o fluxo escolar e as médias de desempenho nas avaliações. Ele é calculado a partir dos dados sobre aprovação escolar, obtidos no Censo Escolar, e das médias de desempenho nas avaliações do Inep, o Sistema de Avaliação da Educação Básica (Saeb) - para as unidades da federação e para o país, e a Prova Brasil para os municípios (disponivel em http://portal.inep.gov.brlideb. Acesso em 06/11/18).
} 


\section{GRÁFICO 6 - Estágio de desenvolvimento educacional dos municípios alcançados pelo Transforma.}

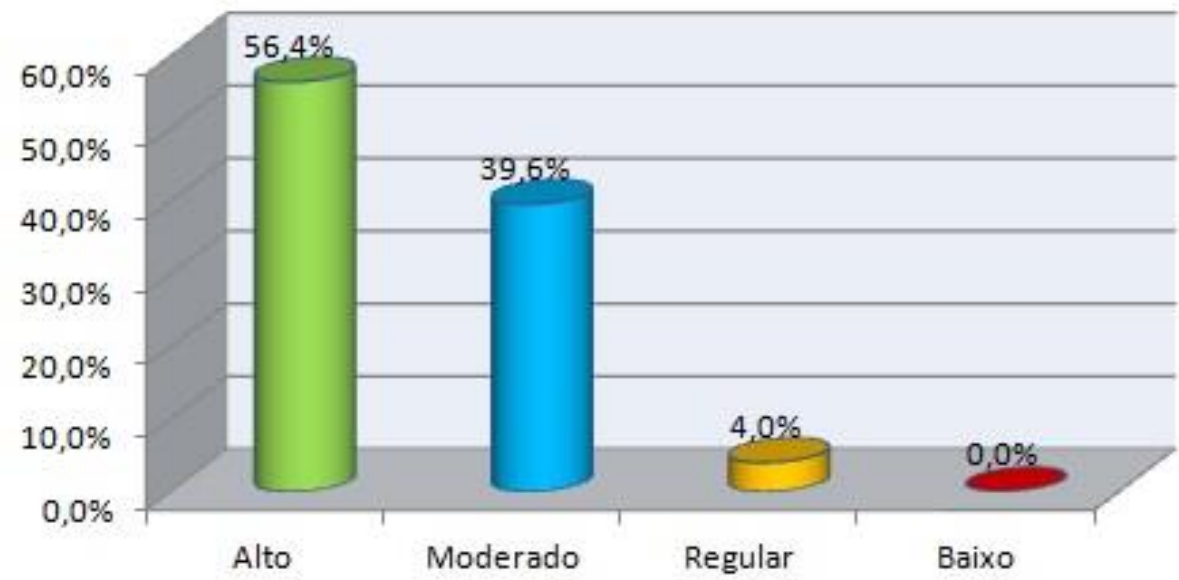

GRÁFICO 7 - Comparação entre o estágio de desenvolvimento educacional dos municípios alcançados pelo Transforma e a média nacional.

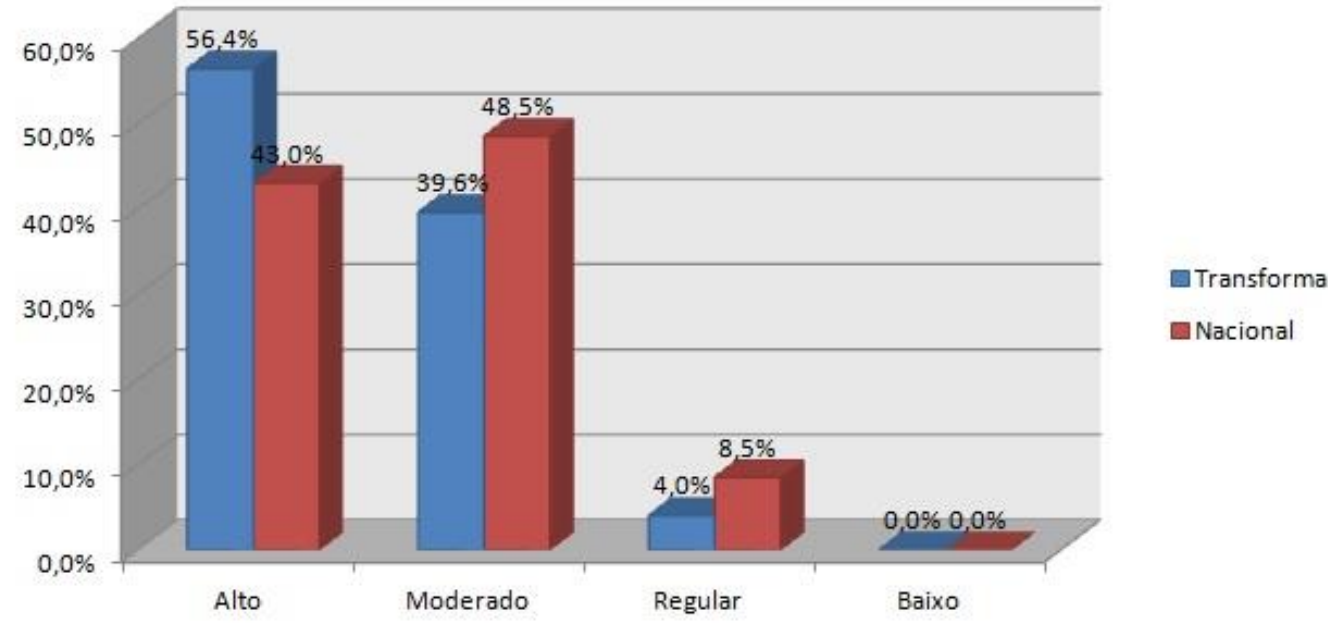

Como a adesão às atividades do programa Transforma eram, em grande medida, uma decisão autônoma de coordenadores e/ou professores, o conjunto destes dados nos permite estabelecer a hipótese de uma relação positiva entre a qualidade do ensino e o envolvimento com atividades que enriquecem a formação educacional ofertada. É claro que baixos níveis de desenvolvimento estão relacionados a causas multifatoriais como níveis de investimento, infraestrutura física, tecnológica, além de outros que limitam 0 acesso a programas fundamentalmente ofertados por via digital como o Transforma.

Em síntese podemos afirmar que:

- As regiões sudeste e nordeste concentraram $78 \%$ de todas as escolas atendidas pelo Transforma, com destaque para a região sudeste, com $55,3 \%$ das escolas atendidas; 
- As regiões sudeste e nordeste concentraram $70,8 \%$ de todos os municípios alcançados pelo Transforma, com o Sudeste concentrando 40,3\% dos municípios;

- $78,6 \%$ das escolas atendidas estão localizadas em municípios do interior dos estados;

- $93,6 \%$ das escolas estão localizadas na zona urbana;

- Dentre o total de professores cadastrados no programa Transforma, $72,4 \%$ atuam na região sudeste, com destaque para Rio de Janeiro (23,7\%), São Paulo (14,4\%) e Minas Gerais (33,0\%).

- O município com a maior concentração de professores foi o Rio de Janeiro, com 10,4\% do total.

- $89 \%$ dos municípios alcançados pelo Transforma tem moderado a alto desenvolvimento.

- $96 \%$ do universo de escolas atendidas estão localizadas em municípios com desenvolvimento educacional alto $(56,4 \%)$ ou moderado $(39,6 \%)$.

\section{CONSIDERAÇÕES FINAIS}

O programa Transforma representou um marco histórico na Educação Olímpica brasileira, elevando seu alcance a níveis nunca vistos. 0 programa alcançou 16 mil escolas, em mais de 3 mil municípios de todos os estados brasileiros. A maior concentração de ações do programa se deu na região sudeste do Brasil. Ao menos dois terços de todos os produtos e serviços ofertados alcançaram professores multiplicadores e, por consequência, estudantes dessa região, principalmente dos estados do Rio de Janeiro, São Paulo e Minas Gerais (71,1\%). A região metropolitana do Rio de Janeiro, que abrigou os Jogos Rio 2016, concentrou 16,4\% dos professores multiplicadores do Transforma. 0 Nordeste foi a segunda região brasileira com maior expressão das ações do Transforma, principalmente em relação ao número de cidades e escolas atendidas. Dentre todas as escolas atendidas pelo Transforma, a maioria (93,6\%) está localizada na zona urbana de municípios do interior dos estados (78,6\%).

A maioria das escolas que participaram do Transforma (89\%) está localizada em municípios que apresentam elevado estágio de desenvolvimento humano nas áreas de emprego e renda, saúde e, destacadamente, no desenvolvimento educacional (96\%). Observa-se, pois, que o maior impacto das ações do programa se deu em escolas que já se destacam a nível nacional pela qualidade de seu ensino, localizadas em municípios com elevado índice de desenvolvimento humano.

Uma vez que a adesão ao programa era voluntária, acreditamos que este é um caso de retroalimentação. As melhores escolas foram as que mais buscaram o programa Transforma, ao passo que a busca por e a implantação de programas extracurriculares como o Transforma colaboram decisivamente no desenvolvimento e qualificação da instituição. Por outro lado, como a principal via de acesso ao programa se deu por meio digital, possivelmente esse tenha sido um fator limitante para professores que atuam em escolas sem livre acesso a recursos digitais.

\section{REFERENCES}

Berbat, V. (2016). Transforma: Relatório final. Documento cedido por Vanderson Berbat. Rio de Janeiro. International Olympic Committee (2014). Olympic Agenda 2020 Lausanne: IOC.

Nikolaus, I. (2013). Pierre de Coubertin's Olympic Idea as an Educational Challenge for the Worldwide Olympic Movement. Kassel: Sportverlag.

Xavier Da Silva, J. (2001). Geoprocessamento para a análise ambiental. Rio de Janeiro: D5 Produção Gráfica. 
Tavares, O. (1998). Mens Fervida in Corpore Lacertoso?: as atitudes dos atletas olímpicos brasileiros frente ao Olimpismo. Dissertação (Mestrado)-PPGEF/UFG, Rio de Janeiro.

Naul, R. et. al (2017). Olympic Education: an international review. Oxford: Routledge.

Firjan (2018). Índice Firjan de Desenvolvimento Municipal: ano base 2016. Sistema Firjan: Junho. https://doi.org/10.21527/2237-6453.2018.45.44-62

\section{(c) (i) (9)}

This work is licensed under a Attribution-NonCommercial-NoDerivatives 4.0 International (CC BY-NC-ND 4.0). 